\title{
Investigation on the Esterification of Fatty Acids Catalyzed by the $\mathrm{H}_{3} \mathrm{PW}_{12} \mathrm{O}_{40}$ heteropolyacid
}

\author{
Abiney L. Cardoso · Rodinei Augusti • \\ Márcio J. Da Silva
}

Received: 17 July 2007/Revised: 5 March 2008/Accepted: 6 March 2008/Published online: 26 March 2008

(c) AOCS 2008

\begin{abstract}
In this work, the $\mathrm{H}_{3} \mathrm{PW}_{12} \mathrm{O}_{40}$ heteropolyacid (HPW) was employed as a homogeneous catalyst to promote the efficient esterification (ethanolysis) of a number of saturated and unsaturated fatty acids (myristic, palmitic, stearic, oleic, and linoleic) under mild reaction conditions. HPW showed a similar activity to those observed for $p$-toluene sulfonic acid (PTSA) and sulfuric acid $\left(\mathrm{H}_{2} \mathrm{SO}_{4}\right)$, the other acidic catalysts we compared them with in this study. In the HPW-catalyzed esterification of stearic acid, the addition of water caused a remarkable decrease in the ethyl stearate yields. On the other hand, the increase in the HPW concentration (up to a maximum value) promoted a proportional improvement in the oleic acid to ethyl oleate conversion. Kinetic measurements using oleic acid as a prototype substrate revealed that the esterification reactions catalyzed by $\mathrm{HPW}, \mathrm{H}_{2} \mathrm{SO}_{4}$, and PTSA are of first-order in relation to the fatty acid concentration. Finally, the catalytic activity of HPW remained unaltered even after several recovery/reutilization cycles whereas the tungsten content in the final product (biodiesel produced by the HPW-catalyzed esterification of oleic acid) was found to be at an acceptably low level (0.0095 $\mathrm{mg}$ of $\mathrm{W}$ per $\mathrm{g}$ of biodiesel).
\end{abstract}

Keywords Catalytic esterification - Heteropolyacids . Free fatty acids $\cdot$ Biodiesel

\footnotetext{
A. L. Cardoso - M. J. Da Silva ( $\varangle)$

Departamento de Química, Universidade Federal de Viçosa,

Viçosa, Minas Gerais 35690-000, Brazil

e-mail: silvamj2003@ufv.br

R. Augusti

Departamento de Química, Universidade Federal Minas Gerais, ICEx, Minas Gerais, Belo Horizonte 31270-901, Brazil
}

\section{Introduction}

Biodiesel, a suitable substitute for petroleum-derived diesel, is a renewable and non-polluting fuel that consists of methyl or ethyl esters resulting from either the transesterification of triglycerides (TG) or the esterification of free fatty acids (FFA) [1]. Currently, most biodiesel is produced from the transesterification of edible resources, such as animal fats, vegetable oils, and even frying oils, using an alkaline catalyst [2-4]. However, the high consumption of catalysts, the formation of soaps, and the low yields, make biodiesel more expensive than petroleum-derived fuel [5].

As an advantageous alternative, acid-catalyzed processes, based mainly on the use of mineral acids, can be applied to produce biodiesel directly from low-cost raw materials that generally contain high amounts of FFA [6]. The production of biodiesel from these kinds of resources can thus comprise two alternative approaches: (1) a two-stage process that requires an initial acid-catalyzed esterification of the free fatty acids followed by a base-catalyzed transesterification of the triglycerides; and (2) a single-process that makes exclusive use of acid catalysts that promote both reactions simultaneously [7]. It must be said, however, that major drawbacks, such as substantial reactor corrosion and generation of great amount of waste, including the salts formed as a result of the mineral acids neutralization, comprise negative and virtually unsurmountable aspects for the acid-catalyzed processes $[8,9]$.

All these problems and the extensive demand for cleaner methodologies have forced the chemical industry to search for environmentally friendly acidic compounds that can be used repeatedly and easily isolated from the reaction products. In addition, such catalysts must have high activity and promote the formation of the required products with elevated selectivity [9-12]. Heteropolyacids (HPA), 
strong Brønsted acids whose acidity has been quantitatively characterized and compared with that of mineral acids [13], have been widely used as homogeneous catalysts for fine chemical synthesis owing mainly to their lower volatility and corrosion power along with their higher activity, selectivity and safety in handling in comparison to conventional mineral acids $[14,15]$. Recent works have shown that the Keggin-type $\mathrm{H}_{3} \mathrm{PW}_{12} \mathrm{O}_{40}$ heteropolyacid (HPW), for which the physicochemical and catalytic properties have been fully described, is an efficient super-acid that can be used either in the homogeneous phase, as it is soluble in different solvents, or in the heterogeneous phase, supported on silica or active charcoal [12-17]. In this way, the $\mathrm{H}_{3} \mathrm{PW}_{12} \mathrm{O}_{40}$ heteropolyacid (HPW) has received a lot of attention in the past few years as it has quickly become a convenient substitute for conventional mineral acids $[17,18]$.

The development of efficient catalysts for the esterification of fatty acids is one of the main challenges to be overcome and such technology could thus allow the production of biodiesel with more competitive costs [5]. For this reason, several researchers all over the world have exhaustively worked on this subject [19-21]. In this paper, the most acidic heteropolyacid in the Keggin series $\left(\mathrm{H}_{3} \mathrm{PW}_{12} \mathrm{O}_{40}\right)$ is evaluated as a homogeneous catalyst for the esterification (ethanolysis) of fatty acids. The effect of the major parameters on the fatty esters production, namely the catalyst concentration, the nature of the fatty acid, and the water content added to the reaction medium, is also investigated. Finally, the ability of the $\mathrm{H}_{3} \mathrm{PW}_{12} \mathrm{O}_{40}$ heteropolyacid (HPW) to be recovered and reutilized in successive catalytic cycles is additionally appraised.

\section{Experimental Procedures}

\section{Chemicals}

All chemicals were purchased from commercial sources and used as received, unless otherwise stated. Ethanol was purified twice by distillation over phosphorous pentoxide. The $\mathrm{H}_{3} \mathrm{PW}_{12} \mathrm{O}_{40} \cdot 10 \mathrm{H}_{2} \mathrm{O}$ heteropolyacid (HPW-dodecatungstophosphoric acid) was purchased from SigmaAldrich (Milwaukee, WI), whereas sulfuric acid $\left(\mathrm{H}_{2} \mathrm{SO}_{4}\right.$, $98 \% \mathrm{~m} / \mathrm{m}$ ) and $p$-toluene sulfonic acid (PTSA) were acquired from Química Moderna (São Paulo, SP, Brazil). Hexane and chloroform were purchased from Vetec (São Paulo, SP, Brazil) and utilized without prior handling. The following fatty acids and their ethyl esters (myristic, palmitic, stearic, oleic, and linoleic) were purchased from Química Moderna (São Paulo, SP, Brazil) and used without further purification.

\section{Reaction Procedure}

Reactions were conducted in a 50-mL three-necked glass flask equipped with a reflux condenser and a conventional thermometer. In all the catalytic tests, ethanol was added in a large molar excess over the fatty acids (50:1) to drive the equilibrium towards the ester formation. In a typical run, a solution of ethanol $(10.0 \mathrm{~mL}, 180 \mathrm{mmol})$ and the fatty acid (3.6 mmol) was heated to the reflux temperature and the catalyst added (PTSA $1.2 \mathrm{mmol} ; \mathrm{H}_{2} \mathrm{SO}_{4} 0.6 \mathrm{mmol}$; or HPW $0.4 \mathrm{mmol}$ ). PTSA and $\mathrm{H}_{2} \mathrm{SO}_{4}$ were selected as they are commonly used as homogeneous catalysts in a number of related investigations [8]. The amount of catalyst used was determined taking into account the number of acidic protons that each species bears, i.e. one for PTSA, two for $\mathrm{H}_{2} \mathrm{SO}_{4}$, and three for $\mathrm{H}_{3} \mathrm{PW}_{12} \mathrm{O}_{40}$. The reaction progress was continuously monitored by taking aliquots at regular intervals and analyzing them via gas chromatography. The reaction yields were calculated by matching the areas of the ethyl esters GC peaks into the corresponding calibration curves. All experiments were performed in triplicate.

\section{Recovery/Reutilization of the HPW Catalyst}

At ambient temperature, diethyl ether and hexane $(5 \mathrm{~mL}$ each) were added to the reaction mixture resulting from the HPW-catalyzed esterification of oleic acid. The alcoholic layer was isolated whereas the non-polar organic layer was washed with several and small portions of water. The aqueous and alcoholic extracts were combined and evaporated till dryness under reduced pressure and the HPW catalyst was then recovered and reutilized. This overall procedure was repeated for three times.

\section{Determination of the Tungsten (W) Content} in the Biodiesel Samples

At ambient temperature, diethyl ether and hexane $(5 \mathrm{~mL}$ each) were added to the reaction mixture obtained upon the esterification of oleic acid (3.6 mmol) catalyzed by HPW $(0.4 \mathrm{mmol})$ and using ethanol $(10.0 \mathrm{~mL}, 180 \mathrm{mmol})$ as solvent. The non-polar organic layer was washed several times with small portions of water and evaporated till dryness under reduced pressure. Three portions of the resulting material (biodiesel) were collected and had their masses exactly determined (each portion weighed ca. $1 \mathrm{~g}$ ). The weighed samples were diluted to $10.00 \mathrm{~mL}$ with nitric acid $1 \%$ (prepared from nitric acid $65 \% \mathrm{v} / \mathrm{v}$ Suprapur ${ }^{\circledR}$, Merck, Darmstadt, Germany). A calibration curve was made based on a stock standard solution of titrisol Tungsten (Merck, Germany) at a concentration of $1 \mathrm{~g} \mathrm{~L}^{-1}$. The measurements were performed with an inductively coupled plasma optical emission spectrometer (ICP-OES), 
model Optima $^{\mathrm{TM}} 2000$ DV (Dual View, PerkinElmer Life and Analytical Sciences, Shelton, CT, USA) with axial (AX-ICP-OES) viewed configuration. The instrument was equipped with a radio frequency source of $40 \mathrm{MHz}$ which provides a power of $0.75-1.5 \mathrm{~kW}$. It utilizes an Echelle grating (79 lines $\mathrm{nm}^{-1}$ ), a solid-state detector, a plasma torch with a $2.0-\mathrm{mm}$ internal diameter injection, and a cross-flow nebulizer coupled with a double-pass Scott-type spray chamber. The equipment was also equipped with an interface (shear gas) that introduces a high air flow perpendicularly to the torch to remove the low temperature of the plasma extremity. The sample introduction system was automated by using the 90 Plus autosampler (PerkinElmer). Other operational parameters were as follows: applied power $1.1 \mathrm{~kW}$; nebulization gas flow $0.9 \mathrm{~L} \mathrm{~min}^{-1}$; auxiliary gas flow $0.2 \mathrm{~L} \mathrm{~min}^{-1}$; plasma gas flow $15 \mathrm{~L} \mathrm{~min}^{-1}$; pumping flow $1.0 \mathrm{~mL} \mathrm{~min}{ }^{-1}$; injector tube diameter $2.0 \mathrm{~mm}$; radially viewed height $14 \mathrm{~mm}$.

Acid-Catalyzed Esterification of Oleic Acid:

Kinetic Measurements

Identical reaction conditions as above described were employed except for the amounts of the catalysts [PTSA (0.02 mmol); $\left.\mathrm{H}_{2} \mathrm{SO}_{4}(0.01 \mathrm{mmol}) ; \mathrm{HPW}(0.0064 \mathrm{mmol})\right]$ and oleic acid $(10 \mathrm{mmol})$ used. Reaction aliquots were taken at regular intervals of $10 \mathrm{~min}$ and the residual oleic acid determined via titration with an alcoholic solution of $\mathrm{KOH}$ [22]. The amount of $\mathrm{KOH}$ needed to neutralize the acidic catalysts (PTSA, $\mathrm{H}_{2} \mathrm{SO}_{4}$, and $\mathrm{HPW}$ ) was determined and this quantity taken into consideration to calculate the real content of the remaining oleic acid in the solution. The experiments were performed in triplicate.

\section{Chromatographic Analyses}

Analyses were carried out on a Shimadzu GC17A gas chromatograph coupled with a MS-QP 5050A mass spectrometer (Tokyo, Japan) with a DB5 capillary column (30 $\mathrm{m}$ length, $0.25 \mathrm{~mm}$ i.d., $0.25 \mathrm{~mm}$ film thickness) and helium as the carrier gas at $2 \mathrm{~mL} / \mathrm{min}$. The temperature program was as follows: $80{ }^{\circ} \mathrm{C}$ for $1 \mathrm{~min}, 10{ }^{\circ} \mathrm{C} / \mathrm{min}$ up to $250{ }^{\circ} \mathrm{C}$, hold time of $5 \mathrm{~min}$. The $\mathrm{GC}$ injector and MS ion source temperatures were kept at 250 and $260{ }^{\circ} \mathrm{C}$, respectively. The MS detector was operated in the EI mode at $70 \mathrm{eV}$, with a scanning range of $\mathrm{m} / \mathrm{z} 50-500$.

\section{Results and Discussion}

\section{General Aspects}

At first, the esterification of the fatty acids with ethanol conducted in the absence of the acidic catalysts (HPW,
$\mathrm{H}_{2} \mathrm{SO}_{4}$, and PTSA), produced no significant yields of the corresponding ethyl esters in spite of the high molar ratio of ethanol/fatty acid (50:1) used (see Experimental section for full details). For instance, only a very low oleic acid to ethyl oleate conversion (ca. 10\%) was achieved even after a reaction time as long as $16 \mathrm{~h}$ (Fig. 1). Conversely, in the presence of HPW and after a reaction time of $10 \mathrm{~h}$ much greater yields $(>86 \%)$ and high selectivities for the ethyl esters $(>93 \%)$ were attained, as concisely displayed in Table 1. Note that such yields and selectivities, in contrast to the results previously described by Wakasugi et al. [23], seem not to be affected by the nature of the fatty acid. For instance, the esterification of myristic acid (bearing a saturated carbonic chain with 14 carbon atoms) and linoleic acid (bearing a carbonic chain with 18 carbon atoms and two double bonds) produced very similar yields (90 and $92 \%$, respectively) and quite analogous selectivities for the corresponding ethyl esters (97 and 93\%, respectively).

Figure 1 shows the yields of ethyl oleate in the esterification of oleic acid catalyzed by HPW, PTSA, and $\mathrm{H}_{2} \mathrm{SO}_{4}$ as a function of reaction time. Note that the reaction yields increase steadily, reach the maximum values (ca. $90 \%$ ) after a reaction time of ca. $10 \mathrm{~h}$ and stay almost invariable afterwards. Furthermore, observe that the three acidic catalysts, in spite of bearing so different structures, displayed quite similar activities as can be confirmed by the attainment of comparable ethyl oleate yields at a given reaction time (Fig. 1). Analogous results were achieved by Misono and coworkers who evaluated the esterification of

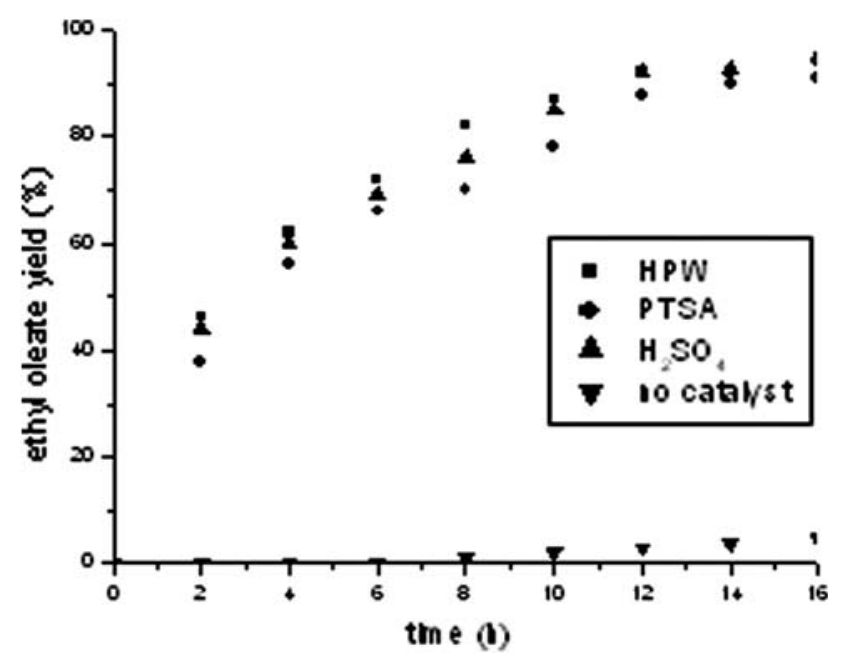

Fig. 1 Ethyl oleate yields (average of the results of three assays) achieved in the ethanolysis of oleic acid catalyzed by the $\mathrm{H}_{3} \mathrm{PW}_{12} \mathrm{O}_{40}$ heteropolyacid (HPW), sulfuric acid $\left(\mathrm{H}_{2} \mathrm{SO}_{4}\right)$, and $p$-toluene sulfonic acid (PTSA) at assorted reaction times. The yields were calculated from the areas of the ethyl oleate GC peak. Reaction conditions: ethanol (180 mmol, $10.0 \mathrm{~mL})$; oleic acid (3.6 mmol); HPW $(0.4 \mathrm{mmol})$ or $\mathrm{H}_{2} \mathrm{SO}_{4}(0.6 \mathrm{mmol})$ or PTSA $(1.2 \mathrm{mmol})$; reflux temperature 
Table 1 Yields and selectivities of the ethyl esters obtained by the esterification of fatty acids catalyzed by the $\mathrm{H}_{3} \mathrm{PW}_{12} \mathrm{O}_{40}$ heteropolyacid (HPW) ${ }^{\mathrm{a}}$

\begin{tabular}{llll}
\hline Fatty acid & $\mathrm{CN}: \mathrm{DB}^{\mathrm{b}}$ & Conversion $(\%)^{\mathrm{c}}$ & Selectivity $(\%)^{\mathrm{c}}$ \\
\hline Myristic & $14: 0$ & 90 & 97 \\
Palmitic & $16: 0$ & 86 & 95 \\
Stearic & $18: 0$ & 87 & 97 \\
Oleic & $18: 1$ & 90 & 95 \\
Linoleic & $18: 2$ & 92 & 93
\end{tabular}

${ }^{a}$ Reaction conditions: ethanol $(180 \mathrm{mmol}, 10.0 \mathrm{~mL})$; fatty acid (3.6 mmol); HPW (0.4 mmol); reflux temperature; reaction time: $10 \mathrm{~h}$

${ }^{b} \mathrm{CN}$ and $\mathrm{DB}$ refer to the number of carbons and double bonds in the carbonic chain of the fatty acids, respectively

c Calculated from the areas of the ethyl esters GC peaks

d Average of the results of three assays

propionic acid in isobutyl alcohol [24]. The authors verified that no significant difference between the catalytic activity of $\mathrm{HPW}$ and $\mathrm{H}_{2} \mathrm{SO}_{4}$ could be noted and proposed that the leveling effect of isobutyl alcohol on the acidity of the first hydrogen ions of both catalysts could likely explain such findings [25]. Distinct results, however, were described by Sepúlveda and coworkers that compared the catalytic activity of $\mathrm{HPW}$ and $\mathrm{H}_{2} \mathrm{SO}_{4}$ in the esterification of acetic acid in ethyl alcohol [26]. The authors verified that, after considering the effective number of acidic protons in each catalyst, HPW showed a higher activity than $\mathrm{H}_{2} \mathrm{SO}_{4}$.

\section{The Effect of the Addition of Water}

The inhibitory effect of water on the ester formation was also evaluated and the results involving the HPW-catalyzed esterification of stearic acid are shown in Fig. 2.

The presence of water drives the esterification equilibrium (Eq. 1) towards the reconstitution of the reactants, i.e. fatty acid and ethanol, thus causing a reduction in the ester formation. Furthermore, it is reasonable to state that the decline in the ester yields could also be caused by a smaller number of available protons as the proportion of coordinating water increases in the reaction medium.

$$
\mathrm{RCOOH}+\mathrm{CH}_{3} \mathrm{CH}_{2} \mathrm{OH} \rightleftharpoons \mathrm{RCOOCH} \mathrm{CH}_{3}+\mathrm{H}_{2} \mathrm{O}
$$

These results seem to indicate that better results could thus be achieved if the acid-catalyzed esterification could be conducted, for instance, in the presence of a water adsorbent agent.

\section{The Effect of the HPW Concentration}

The effect of the HPW concentration on the esterification of oleic acid was investigated and the results are shown in Fig. 3. As a general trend, the increase in the catalyst

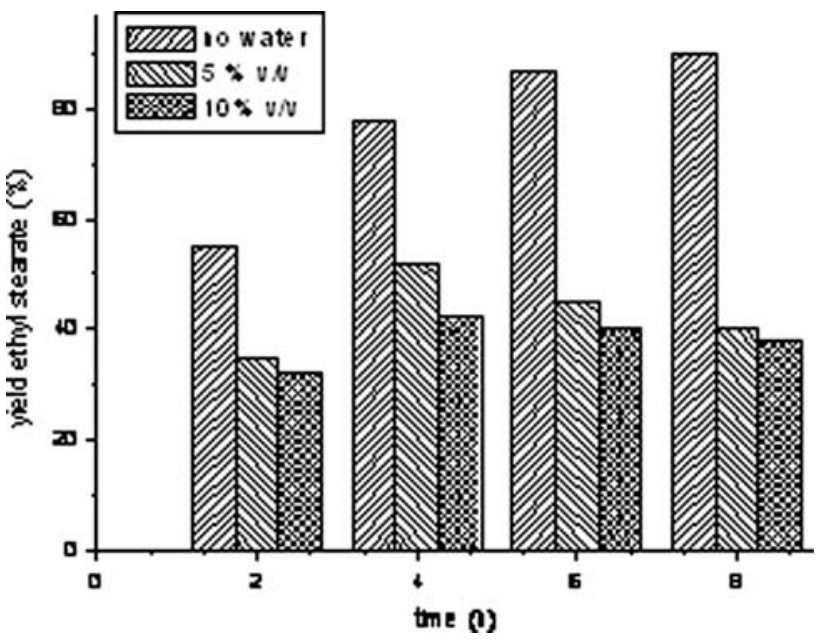

Fig. 2 Ethyl stearate yields (average of the results of three assays) obtained in the HPW-catalyzed ethanolysis of stearic acid conducted under anhydrous conditions and after the addition of 5 and $10 \% \mathrm{v} / \mathrm{v}$ of water. Reaction conditions: ethanol $(180 \mathrm{mmol}, 10.0 \mathrm{~mL})$; stearic acid (3.6 mmol); HPW (0.4 mmol); reflux temperature; reaction time: $10 \mathrm{~h}$

concentration caused a corresponding improvement in the ethyl oleate yields at a given reaction time. However, note that beyond a certain limit (which seems to be $0.04 \mathrm{mmol}$ ) an increase in the amount of catalyst did not cause a remarkable change in the reaction conversion. As clearly shown in Fig. 3, almost identical ethyl oleate yields were achieved when the amount of HPW used was either $0.4 \mathrm{mmol}$ or a tenfold smaller amount $(0.04 \mathrm{mmol})$.

Hence, to avoid unnecessary catalyst expenditure, prior investigations are required to determine the minimum catalyst amount that still leads to a maximum esterification yield.

\section{Acid-Catalyzed Esterification of Oleic Acid:} Kinetic Studies

Kinetic measurements (the concentration of residual oleic acid as a function of time) were performed while the acidcatalyzed reactions were far from their equilibrium positions, a crucial requisite for the attainment of consistent data. Hence, the reactions were conducted by using much smaller (60-fold) catalyst concentrations than in the previous experiments (as the ones described in Fig. 1) and the measurements were performed within the first reaction hour. Furthermore, since the GC column used herein (DB5 capillary) were not appropriate for analyzing fatty acids, the concentration of the residual oleic acid was determined directly from the reaction medium via titration with an alcoholic solution of $\mathrm{KOH}$ [22]. The results from the esterification of oleic acid catalyzed by $\mathrm{HPW}, \mathrm{H}_{2} \mathrm{SO}_{4}$, and PTSA are displayed in Fig. 4. 


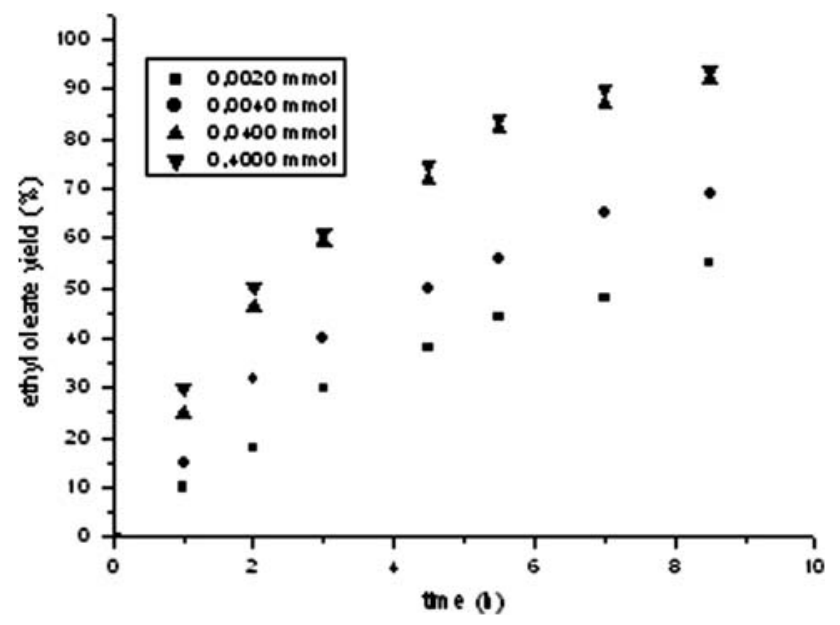

Fig. 3 Ethyl oleate yields (average of the results of three assays) as a function of time achieved in the ethanolysis of oleic acid catalyzed by the $\mathrm{H}_{3} \mathrm{PW}_{12} \mathrm{O}_{40}$ heteropolyacid (HPW) at various concentrations. The yields were calculated from the areas of the ethyl oleate GC peak. Reaction conditions: ethanol (180 mmol, $10.0 \mathrm{~mL})$; oleic acid (3.60 mmol); reflux temperature

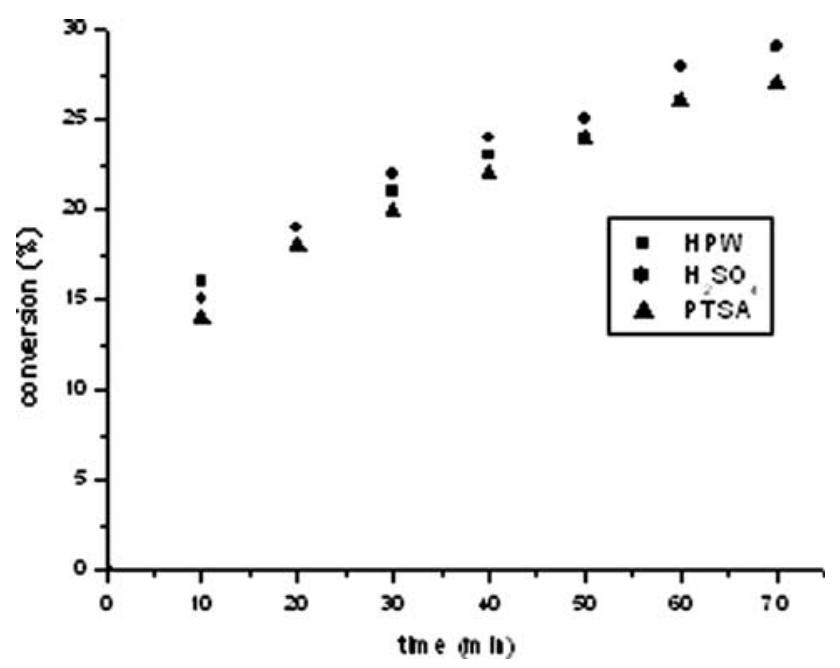

Fig. 4 Conversion yields (average of the results of three assays) as a function of time for the ethanolysis of oleic acid catalyzed by the $\mathrm{H}_{3} \mathrm{PW}_{12} \mathrm{O}_{40}$ heteropolyacid (HPW), sulfuric acid $\left(\mathrm{H}_{2} \mathrm{SO}_{4}\right)$, and $p$ toluene sulfonic acid (PTSA). The residual oleic acid was determined by titration with an alcoholic solution of $\mathrm{KOH}$. Reaction conditions: ethanol (180 mmol, $10.0 \mathrm{~mL})$; oleic acid $(10 \mathrm{mmol})$; HPW (0.0064 mmol) or $\mathrm{H}_{2} \mathrm{SO}_{4}(0.01 \mathrm{mmol})$ or PTSA (0.02 mmol); reflux temperature

To obtain kinetic information, i.e. the reaction order in relation to the oleic acid concentration, plots of $\ln$ [oleic acid] versus time (not shown) were thus built for each acidcatalyzed process. Note that a high molar excess of ethanol in relation to oleic acid (18:1) was used to assure that the ethanol concentration would remain essentially constant during the reaction course.
As displayed in Table 2, the resulting linear equations were found to have high correlation coefficients thus indicating that the reaction is of first order in relation to the oleic acid concentration. From the angular coefficients of such equations, the rate constants $(k)$ and then the half-life times $\left(t_{1 / 2}=k / 0.693\right)$ for each process was thus obtained. The quite similar results for the half-life times (within the experimental uncertainty), as displayed in Table 2, indicate that no remarkable differences among the activity of each acidic catalyst could be clearly verified. These data thus corroborate the results displayed in Fig. 1, which refer to the esterification of oleic acid conducted in the presence of higher catalyst concentrations and monitored for longer reaction times.

The Efficiency of the HPW Catalyst After Successive Recovery/Reutilization Cycles and the Determination of the Tungsten (W) Content in the Biodiesel Samples

The HPW catalyst was recovered at the end of the reaction process and repeatedly utilized to promote the esterification of oleic acid (Table 3).

Note that very high HPW recovery yields were achieved by its extraction from the reaction medium. In addition, a remarkable result was observed as the HPW catalytic activity stayed almost unaltered even after three recovery/ reutilization cycles. Furthermore, it was also verified that the $\mathrm{W}$ content in a sample of biodiesel, prepared via the HPW-catalyzed esterification of oleic acid, was $0.0095 \mathrm{mg}$ of $\mathrm{W}$ per $\mathrm{g}$ of sample (average of three measurements). This significant result indicates that the content of homogeneous tungstate species seems to stay at an acceptably low level in the final product.

In this paper, we can report that the $\mathrm{H}_{3} \mathrm{PW}_{12} \mathrm{O}_{40}$ heteropolyacid (HPW) catalyst was able to efficiently promote the esterification (ethanolysis) of saturated and unsaturated fatty acids in high yields and under mild reaction conditions, with a similar performance to that verified for the other acidic catalysts evaluated here: sulfuric acid $\left(\mathrm{H}_{2} \mathrm{SO}_{4}\right)$

Table 2 Linear equations ( $\ln$ [oleic acid] as a function of time), with the respective correlation coefficients $\left(R^{2}\right)$, obtained from the data displayed in Fig. 4

\begin{tabular}{|c|c|c|c|}
\hline Catalyst & Linear equation $^{\mathrm{a}}$ & $T_{1 / 2}(\min )$ & $R^{2}$ \\
\hline PTSA & $\begin{array}{l}\ln [\text { oleic acid }]=-0.00286 \\
\quad \times t-2.44429\end{array}$ & 242 & 0.9901 \\
\hline HPW & $\begin{array}{l}\ln [\text { oleic acid }]=-0.00336 \\
\quad \times t-2.44143\end{array}$ & 206 & 0.9809 \\
\hline $\mathrm{H}_{2} \mathrm{SO}_{4}$ & $\begin{array}{l}\ln [\text { oleic acid }]=-0.00379 \\
\quad \times t-2.40571\end{array}$ & 183 & 0.9850 \\
\hline
\end{tabular}

The half-life times $\left(t_{1 / 2}\right)$ are given by $0.693 / k$, where $k$ is the rate constant obtained from the angular coefficient of each equation 
Table 3 HPW recovery yields obtained by the extraction procedures and ethyl oleate yields achieved as the result of the ethanolysis of oleic acid promoted by the recovered HPW

\begin{tabular}{lll}
\hline Run $^{\text {a }}$ & Ethyl oleate yield $(\%)^{\mathrm{b}}$ & Recovery rates $(\%)^{\mathrm{c}}$ \\
\hline 1 & 92 & $>98$ \\
2 & 90 & $>98$ \\
3 & 88 & $>97$
\end{tabular}

a Reaction conditions: ethyl alcohol (180 mmol, $10.0 \mathrm{~mL})$; oleic acid (3.60 mmol); HPW (0.4 mmol); reflux temperature; reaction time: $10 \mathrm{~h}$

${ }^{b}$ Calculated from the areas of the ethyl oleate GC peak

c In relation to the initial catalyst mass

and $p$-toluene sulfonic acid (PTSA). In the HPW-catalyzed reactions, the presence of water caused a strong inhibition of the ethyl stearate formation whereas a tenfold decrease in the catalyst amount (from 0.4 to $0.04 \mathrm{mmol}$ ) did not cause a detectable reduction in the ethyl oleate yields. Kinetic measurements revealed that the acid-catalyzed esterification is of first-order in relation to the fatty acid concentration. Furthermore, it was also demonstrated that the catalytic activity of HPW remained unaltered even after several recovery/ reutilization cycles and that the tungsten content in the final product was found to be at an acceptably low level. Because of that, the use of HPW represents a remarkable improvement compared to $\mathrm{H}_{2} \mathrm{SO}_{4}$ and PTSA and such a catalyst can quickly become a viable alternative to produce biodiesel at lower costs, especially when it is intended to use oils containing a high proportion of free fatty acids.

Acknowledgments We acknowledge the financial support from the Brazilian research agencies FAPEMIG and CNPq. The authors are also indebted to Prof. J. B. B. da Silva (UFMG) for his invaluable assistance in obtainingf the ICP data.

\section{References}

1. Maa F, Hanna MA (1999) Biodiesel production-a review. Bioresour Technol 70:1-15

2. Srivastava A, Prasad R, (2000) Triglycerides-based diesel fuels. Renew Sustain Energy Rev 4:111-133

3. Kima HJ, Kang BS, Kim MJ, Park YM, Kimb DK, Lee JS, Lee KY (2004) Transesterification of vegetable oil to biodiesel using heterogeneous base catalyst, Catal Today 93-95:315-320

4. Haas MJ, Karen MS, Marmer WN, Foglia TA (2004) In situ alkaline transesterification: an effective method for the production of fatty acid esters from vegetable oils. J Am Oil Chem Soc 81:83-89

5. Haas MJ (2005) Improving the economics of biodiesel production through the use of low value lipids as feedstocks: vegetable oil soapstock. Fuel Process Technol 86:1087-1096

6. Lotero E, Liu Y, Lopez DE, Suwannakarn K, Bruce DA, Goodwin JG (2005) Synthesis of biodiesel via acid catalysis. Ind Eng Chem Res 44:25353-25363
7. Zullaikah S, Lai CC, Vali SR, Ju YH (2005) A two-step acidcatalyzed process for the production of biodiesel from rice bran oil. Bioresour Technol 96:1889-1896

8. Corma A, Garcia H (2003) Lewis acids: from conventional homogeneous to green homogeneous and heterogeneous catalysis. Chem Ver 103:4307-4365

9. Marchetti JM, Miguel VU, Errazu AF (2007) Heterogeneous esterification of oil with high amount of free fatty acids. Fuel 86:906-910

10. Goff MJ, Bauer NS, Lopes S, Sutterlin WR, Suppes GJ (2004) Acid-catalyzed alcoholysis of soybean oil. J Am Oil Chem Soc $81: 415-420$

11. Misono M, Izumi O, Koyano G, Aoshima A (2000) Heteropolyacids versatile green catalysts usable in a variety of reaction media. Pure Appl Chem 72:1305-1311

12. Misono M, Misono CR (2000) Acid catalysts for clean production. Green aspects of heteropolyacid catalysts. Acad Sci Paris Serie II Chim Chem 3:471-475

13. Timofeeva MN (2003) Acid catalysis by heteropoly acids. Appl Catal 256:19-35

14. Kozhevnikov IV (2002) Catalysts for fine chemicals, catalysis by polyoxometalates, vol 2, Wiley \& Sons, Chichester

15. Kozhevnikov IV (1998) Catalysis by heteropoly acids and multicomponent polyoxometalates in liquid-phase reactions. Chem Rev 98:171-198

16. Timofeeva MN, Matrosova MM, Il'inich GN, Reshetenko TV, Avdeeva LB, Kvon RI, Chuvilin AL, Budneva AA, Paukshtis EA, Likholobov VA (2003) Esterification of $n$-butanol with acetic acid in the presence of $\mathrm{H}_{3} \mathrm{PW}_{12} \mathrm{O}_{40}$ supported on mesoporous carbon materials. Kinet Catal 44:778-787

17. Narasimharao K, Brown DR, Lee AF, Newman AD, Siril PF, Tavener SJ, Wilson K (2007) Structure-activity relations in Csdoped heteropolyacid catalysts for biodiesel production. J Catal 248:226-234

18. Alizadeh MH, Kermani1 T, Tayebee R (2007) A method for the acetylation of alcohols catalyzed by heteropolyoxometallates. Monatshefte fur Chemie 138:165-170

19. Abreu FR, Lima DG, Hamú EH, Einloft S, Rubim JC, Suarez PAZ (2003) New metal catalysts for soybean oil transesterification. J Am Oil Chem Soc 80:601-604

20. Meneghetti SMP, Meneghetti MR, Wolf CR, Silva EC, Lima GES, Coimbra MA, Soletti JI, Carvalho SHV (2006) Ethanolysis of castor and cotton seed oil: a systematic study using classical catalysts. J Am Oil Chem Soc 83:819-822

21. Reis SCM, Lachter ERR, Nascimento RSV, Rodrigues JA, Reid MG (2005) Transesterification of Brazilian vegetable oils with methanol over ion-exchange resins. J Am Oil Chem Soc 82:661665

22. Berrios M, Siles J, Martın MA (2007) A kinetic study of the esterification of free fatty acids (FFA) in sunflower oil. Fuel 86:2383-2388

23. Wakasugi K Misaki T, Yamada K, Tanabe Y (2000) Diphenylammonium triflate (DPAT): Efficient catalyst for esterification of carboxylic acids and for transesterification of carboxylic esters with nearly equimolar amounts of alcohols. Tetrahedron Lett 41:5249-5252

24. Mizuno N, Misono M (1994) Studies of the activity of catalysts based on heteropolyacids. J Mol Catal A 86:319-342

25. Hu C, Hashimoto M, Okuhara T, Misono M (1993) Catalysis by heteropoly compounds, XXII. Reactions of esters and esterification catalyzed by heteropolyacids in a homogeneous liquid phase-effects of the central atom of heteropolyanions as the addenda atom. J Catal 143:437-448

26. Sepulveda JH, Yori JC, Vera CR (2005) Repeated use of supported $\mathrm{H}_{3} \mathrm{PW}_{12} \mathrm{O}_{40}$ catalysts in the liquid phase esterification of acetic acid with butanol. Appl Catal 288:18-24 